\title{
O PERÍODO DE INCUBAÇÃO E PÓS-INCUBAÇÃO DAS PEQUENAS EMPRESAS DE BASE TECNOLÓGICA
}

\author{
Pedro Henrique de Oliveira ${ }^{1}$ \\ Ana Cláudia Fernandes Terence ${ }^{2}$ \\ Marco Antonio Catussi Paschoalotto ${ }^{3}$
}

\section{Resumo}

O objetivo desse trabalho foi analisar o período de incubação e pós-incubação das pequenas empresas de base tecnológica. Acrescente-se que muitas EBT de pequeno porte iniciam suas atividades em incubadoras de empresas. Incubadoras de empresas são entidades promotoras de empreendimentos inovadores. A incubadora de empresas tem por objetivo oferecer suporte a empreendedores para que eles possam desenvolver ideias inovadoras e transformá-las em empreendimentos de sucesso. Para tanto, oferecem infraestrutura e suporte, por meio de orientação aos empreendedores quanto à gestão, entre outras questões essenciais ao desenvolvimento de uma empresa. Muitas EBT iniciam suas atividades amparadas pelo suporte de uma incubadora de empresas e, após um determinado período, desempenham suas atividades sem a sinergia proporcionada pela estrutura (física e de negócios) da incubadora. Para atingir o objetivo proposto foi realizado um estudo multicasos em 04 empresas de base tecnológica situadas em São Carlos-SP, caracterizado como qualitativo e exploratório. Na coleta de dados foram realizadas entrevistas junto aos gestores das empresas e ao gestor da incubadora. A incubação é outro aspecto relevante no contexto de desenvolvimento dessas empresas, devido a serem criadas por pessoal altamente qualificado e de formação técnica, as empresas passam por dificuldades e crises, advindas de problemas administrativos e gerenciais. Com os benefícios oferecidos pela incubadora de empresas, as EBT conseguem sanar tais dificuldades e obter uma orientação específica de mercado. A sinergia encontrada na incubadora também é motivo de destaque. O ambiente em que encontram é favorável para o desenvolvimento de novas práticas. Nas empresas graduadas, percebe-se uma maior maturidade administrativa, afetando o processo de criação de estratégias e as práticas de inovação que tendem a ficar mais formais. Pretendeu-se colaborar para diminuir a lacuna existente sobre o período de incubação das pequenas empresas de base tecnológica, à medida que se propõe considerar as especificidades das pequenas empresas.

Palavras-chave: incubação; pós-incubação; estratégia; pequena empresa; inovação; empresa de base tecnológica.

\begin{abstract}
The purpose of this paper was to analyze the period of incubation and post-incubation in technology based small business (EBT). It should be added that many small EBT begin their activities in business incubators. Business incubators are organizations that promote innovative projects. The business incubator is designed to provide support to entrepreneurs so that they can develop innovative ideas and transform them into successful enterprises. To do so, provide infrastructure and support through guidance to entrepreneurs on management, among other key issues for the development of a company. Many EBT begin their activities supported by the support of a business incubator and, after a certain period, perform their activities without the synergy provided by the structure (physical and business) of incubator. To achieve this purpose it was conducted a study multicases in 04 technology-based companies located in São Carlos-SP, characterized as qualitative and exploratory. Data collection interviews were conducted with the managers of the companies and the incubator manager. Incubation is another important aspect in the context of development of these companies. Because they are created by people highly skilled and technical training, companies experience difficulties and crises arising from administrative and

\footnotetext{
${ }^{1}$ Mestrando em Engenharia de Produção na Escola de Engenharia de São Carlos da Universidade de São Paulo (EESC/USP).

${ }^{2}$ Professora Doutora do Departamento de Administração Pública da Faculdade de Ciências e Letras da Universidade Estadual Paulista "Júlio de Mesquita Filho" (FCLAr/UNESP).

${ }^{3}$ Mestrando em Organizações na Faculdade de Administração e Economia de Ribeirão Preto da Universidade de São Paulo (FEA-RP/USP).
} 
managerial problems. With the benefits offered by the business incubator can remedy these difficulties and get a specific market orientation. The synergy found in the incubator is also prominent reason. The environment in which they are favorable for the development of new practices. In the graduated companies, perceive a greater administrative maturity, affecting the process of creating strategies and innovative practices that tend to be more formal. It was intended to work together to reduce the gap on the incubation period of small technology-based companies, as it is proposed to consider the specificities of small business

Keywords: incubation; post-incubation; strategy; small business; innovation; technology-based company.

Indicação área ABEIN: Área 6 - Inovação, desenvolvimento e sustentabilidade

Classificação JEL: O3 Innovation; Research and Development; Technological Change; Intellectual Property Rights; O31 Innovation and Invention: Processes and Incentives.

\section{Introdução}

As pequenas empresas compreendem a maioria dos estabelecimentos industriais, comerciais e de serviços. Existem, no Brasil, cerca de 6 milhões de empresas, das quais 99\% são micro e pequenas. As micro e pequenas empresas são responsáveis por 60\% das pessoas ocupadas no setor privado formal e informal (incluem-se, neste cálculo, os empregados, os empresários e os indivíduos que possuem seu próprio negócio, mas não têm empregados). Acrescente-se que, as micro e as pequenas empresas representam 20\% do Produto Interno Bruto (PIB) brasileiro e 36\% das compras públicas (PORTAL BRASIL, 2013). A relevância desse segmento de empresas advém não apenas do número de estabelecimentos e de sua abrangência, pois oferece outras contribuições, como: absorve mão-de-obra, gerando emprego e renda; desenvolve tecnologia e inovações que atendem a mercados específicos; facilita a dispersão da atividade manufatureira; diminui os desequilíbrios regionais, desempenhando importante papel na interiorização do desenvolvimento; estimula a competição e contribui para a pulverização do mercado (TERENCE, 2008).

Nos últimos anos, pesquisas têm se voltado para o universo das pequenas empresas, contribuindo para uma abordagem adequada de suas características e construção de conhecimento sobre o setor. Alguns estudos demonstram que as teorias das grandes organizações não se aplicam integralmente às empresas de menor porte, em especial pelo fato de que não explicam ou consideram o comportamento do dirigente (DANDRIGE, 1979; D’AMBOISE, MULDOWNEY, 1988; DAY, 2000). Acredita-se que outros aspectos devam ser levados em conta, pois, embora a literatura relacionada a pequenas empresas tenha começado a se desenvolver nos últimos anos, poucos estudos concentram-se nas suas especificidades de gestão.

As Empresas de Base Tecnológica (EBT) constituem uma categorização do universo empresarial que recorta transversalmente as classificações setoriais. Em estudo realizado no estado de São Paulo, Fernandes, Côrtes e Oishi (2000) concluem que as EBT são, em sua maioria, de pequeno porte e jovens (menos de 10 anos). Vale ressaltar também que as EBT enfrentam muitas dificuldades internas e externas em sua consolidação. Entre as internas, as mais citadas são: poucos recursos financeiros para investir e capacitação gerencial deficiente. A propósito estas empresas, em especial as de pequeno porte, no processo de concretizar sua efetividade, encaram problemas internos, como a não utilização de técnicas administrativas, a falta de habilidade para comercializar tecnologias e, em particular, na área gerencial, a escassez de recursos humanos e inexistência de capacitação formal dos dirigentes (TERENCE, 2008).

Outra característica importante é que as EBT têm a inovação como premissa de conceituação e condição de crescimento, desenvolvimento e mesmo sobrevivência, ao passo que inovar implica desenvolver atividades de modo diferente daquele utilizado em uma organização, tomar iniciativas para a melhoria de produtos, processos ou procedimentos, aumentando o seu valor e desempenho (DAMANPOUR, 1996).

Considerando que a inovação é crucial para a sobrevivência de empresas em ambientes competitivos e em constante transformação (AUDRESTCH, 1995), pretende-se focar práticas de inovação das EBT de acordo com o seu processo de criação de estratégias. Acrescente-se que muitas EBT de pequeno porte iniciam suas atividades em incubadoras de empresas. 
Incubadoras de empresas são entidades promotoras de empreendimentos inovadores com o objetivo de oferecer suporte a empreendedores para que eles possam desenvolver ideias inovadoras e transformá-las em empreendimentos de sucesso (ANPROTEC, 2013). Para tanto, oferecem infraestrutura e suporte, por meio de orientação aos empreendedores quanto à gestão, entre outras questões essenciais ao desenvolvimento de uma empresa.

Segundo dados da ANPROTEC (2013), o Brasil conta com 384 incubadoras, que abrigam 2.649 empresas e geram 16.394 postos de trabalho, sendo que $98 \%$ das empresas incubadas inovam nos âmbitos local (28\%), nacional (55\%) e mundial (15\%), com destaque para as incubadoras nacionais, que graduaram nas últimas três décadas 2.509 empreendimentos.

Ao completarem o período de incubação as empresas são graduadas e deixam de desfrutar da sinergia obtida nas condições de incubação proporcionada do uso compartilhado da planta industrial, instalações físicas, apoio de pessoal qualificado, equipamentos e ferramentas administrativas, transferência de P\&D e tecnologia (ARAGÃO, 2005). A autora argumenta que o apoio às empresas deveria se estender ao período de pós-incubação, para manter a sinergia, por meio de um programa de pós-incubação. No entanto, não existe uma sistematização de programas de pós-incubação de empresas no Brasil. Existem iniciativas isoladas, como Campinas e Florianópolis, por exemplo.

Tumelero (2012) estima que o número de EBT pós-incubadas chegue a 1.300 empresas e destas apenas 40 a $60 \%$ continuam em operação, sendo as demais extintas ou empresas que passaram por processos de fusão ou aquisição. O autor identifica nos resultados de sua pesquisa que os empreendedores das EBT reconhecem a inovatividade (necessidade de geração contínua de inovações) como forma de garantir a sobrevivência das empresas pós-incubadas.

Com toda contextualização do cenário vivido pelas EBT e o processo de incubação, o objetivo desse trabalho foi analisar o período de incubação e pós-incubação das pequenas empresas de base tecnológica. Em complemente ao objetivo geral, o objetivo específico procura compreender o papel da incubadora para as pequenas empresas de base tecnológica.

Por fim, as empresas de base tecnológica (EBT) somam, em sua gestão, problemas e características particulares. Porque atuam em ramos bastante específicos, utilizando tecnologias próprias e ainda não padronizadas, apresentam uma grande variedade de alternativas de projeto e produto (SEBRAE, 2001) que precisa ser considerada. Apesar do interesse dos pesquisadores por estas organizações, tem-se pouco conhecimento acumulado sobre suas características, especialmente de gestão e de suas práticas de inovação. Além disso, são poucos também os estudos sobre as incubadoras e período de incubação e posterior pós-incubação das pequenas empresas. Acrescente-se que as EBT têm dificuldades para obter recursos financeiros e mostram-se deficientes na capacitação gerencial dos empreendedores, problemas que se reforçam mutuamente como obstáculos à sua consolidação.

Este artigo, de caráter exploratório, pretendeu contribuir com resultados que possibilitem o desenvolvimento de novas pesquisas relacionadas ao processo de incubação de empresas, bem como estudos referentes à elaboração de políticas públicas voltadas ao segmento de pequenas empresas e ao setor de empresas de base tecnológica.

Este artigo encontra-se dividido em cinco partes, sendo a primeira constituída por essa introdução, que explicita as características das pequenas empresas e sobre o processo de incubação e pós-incubação de empresas. A segunda parte é composta da revisão bibliográfica sendo constituída de três partes: 1) incubadora de empresas em outros países; 2) incubadoras de empresas no Brasil e; 3) status de incubação. A terceira parte é composta do método de pesquisa e do processo de incubação e pós-incubação das pequenas empresas, sendo exposta pelas empresas entrevistadas (empresa incubada 01, empresa incubada 02, empresa graduada 03 e empresa graduada 04). Por fim, na quarta parte foi realizada a discussão dos dados e na quinta foi feita uma conclusão.

\section{Revisão bibliográfica}

Antes de se definir os três estágios de incubação definiu-se um roteiro para o entendimento sobre o processo de incubação a partir da experiência internacional e da experiência brasileira explorando temas como o surgimento de incubadoras, números de incubadoras existentes, número de incubadoras abrigadas etc. 


\section{1. Incubadora de empresas em outros países}

A partir do estudo da experiência internacional chega-se ao entendimento do processo de criação das incubadoras, a sua evolução, a sua importância e também a diferença de incubação de empresas entres os países.

As primeiras duas iniciativas de que se pode considerar uma incubadora ou parque tecnológico, segundo Adkins apud Aragão (2005) são: 1) em 1959 a partir do Centro Industrial Batavia e; 2) em 1964 com a University City Science Center (UCSC). Porém, de fato, as primeiras incubadoras dos Estados Unidos, segundo Stevenson e Thomas apud Aragão (2002) foram criadas em 1970 a partir de prédios abandonados, pesquisas de universidades e indivíduos empreendedores com o objetivo de criação, sobrevivência e crescimento com apoio em atividades gerenciais, serviços administrativos, acesso a financiamentos durante os primeiros anos de existência.

Alguns exemplos famosos de incubadoras são o Vale do Silício, no estado da Califórnia e a Rota 128, no estado de Massachussetts. Cita-se outros exemplos de experiência de Incubação pelo mundo a partir de Aragão (2005) que são: Canadá, com uma sólida infraestrutura de apoio à inovação de micro e pequenas empresas, em que existem somente na província de Quebec 10 empresas incubadas; Europa, com criação de incubadoras de empresas a partir de meados da década de 1980 oferecendo para as empresas serviços de apoio financeiro, consultorias e treinamento, vale ressaltar que o processo de incubação se desenvolveu quase que ao mesmo tempo na Alemanha, França e Reino Unido; China, o processo de incubação iniciou-se em 1987, contando atualmente com mais de 130 incubadoras de negócios de alta tecnologia no país; no Japão destaca-se a existência de Cidades Tecnológicas que devem contar com toda a infraestrutura necessária para o funcionamento como existência de realização de negócios, universidade, instituto de pesquisas, além de estar em um local estratégico sendo localizada próximo de uma grande cidade, aeroporto e estação ferroviária. Existem 19 cidades escolhidas para a realização do programa Cidades Tecnológicas; Israel, com destaque para o Programa de Incubadoras de Tecnologia em 1991. Atualmente conta com 26 incubadoras de empresas; Rússia, em 1991 foram fundados o Instituto Federal de Tecnologia Eletrônica de Moscou (MIET) e o Parque Científico e Tecnológico de Zelenograd (ZSTP), com apoio principal das universidades para início das atividades de novos pequenos negócios.

Assim, percebe-se que ao redor do mundo existem atividades de incubação, tendo como início em 1959 a partir do Centro Industrial de Batavia. Tal fato corrobora para a importância das incubadoras de empresas para o início das atividades das empresas.

Percebem-se, a partir de Aragão (2005), particularidades dos programas de incubação internacional diferentes dos encontrados no programa brasileiro tais como:

- Formas de captação, em que nos Estados Unidos ocorre por meio de doações privadas e em Israel por negociações de ações nas bolsas de valores;

- Contratações de consultorias: nos Estados Unidos estudantes de MBA prestam consultoria em planos de negócios e no Canadá consultores contratados recebem salários para tal função;

- Espaço físico, em que na China se reutiliza plantas industriais desativadas para o serviço de incubação e;

- Prazo de graduação, em que na Rússia não se adota prazos para a graduação das empresas.

\subsection{Incubadora de empresas no Brasil}

Uma incubadora pode ser definida como uma entidade que tem como objetivo fornecer suporte para que os empreendedores possam desenvolver ideias para transformá-las em empreendimentos de sucesso, oferecendo infraestrutura, capacitação, suporte gerencial e orientações (administrativo, comercial, financeiro e jurídico) para que a empresa se desenvolva (ANPROTEC, 2012). O SEBRAE (2012) define incubadora como um ambiente que visa difundir o empreendedorismo e o conhecimento. Apoia projetos novos e inovadores com suporte necessário para o seu desenvolvimento, fomentando o apoio à micro e pequenas empresas com ajuda de instituições de ensino e pesquisa, órgãos governamentais e iniciativa privada. 
Existem alguns pontos comuns nas incubadoras de acordo com a Associação Nacional de Entidades Promotoras de Empreendimentos Inovadores (ANPROTEC, 2012), o que estabelece um padrão mínimo em sua conceituação, como a disponibilização de espaço, oferecimento de serviços como limpeza e secretaria, além de serviços de capacitação e apoio, como por exemplo, consultorias, e criação de empregos e dinamização da economia, sem fins lucrativos na maioria dos casos.

Os objetivos das incubadoras devem ser baseados em seus propósitos, visando impactos positivos para a sociedade e economia, necessitando de mecanismos de gestão e esforços diferenciados. Assim, os objetivos mais frequentes das incubadoras são: dinamização da economia local, criação de spins-off (transferência de tecnologia e conhecimento das universidades para as empresas), dinamização de setor específico de atividade, inclusão socioeconômica, geração de emprego e renda. (ANPROTEC, 2012, p. 12).

De acordo com ANPROTEC (2012) existem diversos tipos de incubadoras: de base tecnológica, em que incubam empresas do setor de tecnologia; tradicionais, com empreendimento de setores tradicionais da economia; mistas, que abrigam empresas tanto do setor tecnológico quanto dos setores tradicionais e; as sociais, como cooperativas e associações populares.

O SEBRAE (2012) define os tipos de incubadoras de empresas em: 1) uso intensivo de tecnologia e 2) desenvolvimento local e regional. O propósito da incubadora de empresas de uso intensivo de tecnologia é apresentado como:

\begin{abstract}
Apoia empresas atuantes em setores tecnologicamente dinâmicos e que tenham na inovação tecnológica o diferencial do seu negócio. Abriga empresas de base tecnológica cujos produtos, serviços ou processos possuem alto valor agregado devido à utilização de algum tipo de tecnologia ou de pesquisas científicas. Geralmente reúne empreendimentos nos setores de biotecnologia, química, mecânica de precisão etc. O resultado das empresas assistidas deverá ter impacto econômico, social e científico em âmbito nacional e/ou internacional. (SEBRAE, 2012, p. 3)
\end{abstract}

Já da incubadora de empresas de desenvolvimento local e regional é apresentado como:

\begin{abstract}
“Apoia empresas de setores tradicionais da economia (indústria e prestação de serviços) que agregam tecnologia e inovação de seus produtos, processos e serviços. Essas empresas detêm tecnologia largamente difundida e agregam valor por meio de um incremento no nível tecnológico que empregam. O resultado das empresas assistidas deverá ter impacto econômico e social em âmbito local e/ou regional. (SEBRAE, 2012, p.3)
\end{abstract}

No Brasil existem mais de 384 incubadoras de empresas, sendo a maioria caracterizada como base tecnológica. Tem destaque no ranking mundial de incubadoras ocupando o quarto lugar. Como já exposto anteriormente, também tem diferença quanto à forma de capacitação de recursos, sendo geralmente de recursos federais, enquanto nos Estado Unidos acontece por recursos privados, por exemplo (ANPROTEC, 2012; TUMELERO, 2012; ANPROTEC, 2013).

As 384 incubadoras brasileiras em operação no Brasil abrigam 2.640 empresas, com geração de mais de 16.000 empregos. Já foram graduados mais de 2.500 empreendimentos que faturam em média R\$ 4 bilhões e empregam mais de 29.000 pessoas (ANPROTEC, 2012). Esses dados também são expostos no quadro 1 logo a baixo.

\begin{tabular}{|c|c|}
\hline \multicolumn{2}{|c|}{ Dados sobre as incubadoras ANPROTEC (2012) } \\
\hline Número de incubadoras & 384 \\
\hline Número de empresas incubadas & 2640 \\
\hline Número de empregos diretos gerados & mais de 16000 \\
\hline Número de empresas graduadas & 2500 \\
\hline Faturamento médio & 4 bilhões de reais \\
\hline Número de empregos indiretos gerados & 29000 \\
\hline
\end{tabular}

Quadro 1 - Dados sobre as incubadoras de empresas ANPROTEC (2012) 
Por fim, considera-se que as incubadoras de empresas no Brasil têm início recente. A primeira incubadora criada no Brasil foi na cidade de São Carlos no ano de 1985, com o apoio do CNPq, Conselho Nacional de Desenvolvimento Científico e Tecnológico (MCTI, 2001).

Carvalho e Galina (2015) trazem alguns pontos importantes sobre as incubadoras como inovação empresarial. Assim é necessária a discussão de como elas são formadas e geridas, fatores de sucesso, como objetivos econômicos e tecnológicos, criação de empregos e estabelecimento de uma sociedade empreendedora, além da análise de ambiente da região como fornecedora de condições para o desenvolvimento das incubadoras. A análise de uma incubadora então pode ser pensada em três pontos, infraestrutura, rede de contatos e serviços empresariais. Oferecem a infraestrutura para o estabelecimento dos escritórios, sala de reuniões, espaços de convivências e laboratórios; oferecimento de serviços empresariais como seminários e treinamentos sobre finanças, marketing, propriedade intelectual, ou seja, serviços gerenciais e técnicos, com falta de treinamentos e informações sobre serviços contábeis e jurídicos e; acesso a uma rede de contatos como outras empresas e acesso a financiamentos.

A incubadora é um processo de treinamento de organizações para seu funcionamento adequado. Envolve o conhecimento teórico para a prática das organizações, transformando um tipo de conhecimento em outros tipos de conhecimento, como cultural, artístico, de gestão. O movimento de incubadoras no Brasil representou uma nova direção para as políticas de ciência, tecnologia e indústria para a América Latina. Ocasionou o desenvolvimento de baixo custo, com os benefícios oriundos das universidades, indústria e recursos governamentais. Percebe-se também ações municipais para o desenvolvimento desse tipo de empreendimento (ETZKOWITZ, MELLO, ALMEIDA, 2005).

Etzkowitz, Mello, Almeida (2005) colocam que as incubadoras no Brasil são concebidas como uma adaptação de um modelo internacional, com a entrada de novos atores de mecanismos adaptados para atingir seus objetivos. Como desenvolvimento do modelo brasileiro de incubadoras apresentam um regime descentralizado e democrático, com participação da sociedade civil, além da participação do governo, associações de industrias e das universidades; formação de organizações hibridas, sendo mais produtivas do que as empresas individuais das quais eram constituídas, com apoio em tecnologias e parcerias com o governo, indústria e universidades e; formulação de política e projetos a nível municipal formando uma rede de cooperação com uma infraestrutura para inovação, rede de contatos e programas de empreendedorismo.

Existem vários tipos de incubadora no Brasil como incubadoras de base tecnológica, incubadoras tradicionais, incubadoras de cooperativas e incubadoras privadas. Cada um desses tipos de incubadora apresenta características próprias. A análise se baseia em três pilares: fonte de conhecimento, parcerias e fonte de financiamento. Assim, a incubadora de base tecnológica, em que fora feito os estudos de caso, apresenta como características uma necessidade de menor de recursos para o seu estabelecimento, papel das universidades para o desenvolvimento das incubadoras, além de parcerias com o governo e com o setor industrial em financiamento e desenvolvimento de tecnologia (ALMEIDA, 2005). Outras importantes instituições para as incubadoras são a ANPROTEC (Associação Nacional de Entidades promotoras de empreendimentos empreendedores) e o FINEP (Financiadora de Estudos e Projetos).

\subsection{Status de incubação}

De acordo com o SEBRAE (2012), existem alguns tipos de status de incubação: pré-incubação; incubação; pós-incubação; graduação; não residente/associada; desistente; desativada e; desvinculada. No trabalho são abordados todos os status, com ênfase nos três primeiros tipos (Pré-incubação, Incubação e Pós-incubação) devido ao objetivo proposto nesta investigação. Esses dados são apresentados também do quadro 2 logo a baixo.

Status de incubação de empresas SEBRAE (2012)

1) Pré-incubação

2) Incubação

3) Pós-incubação

4) Não residente/associada 


\begin{tabular}{|c|} 
5) Desistente \\
\hline 6) Desativada \\
\hline 7) Desvinculada
\end{tabular}

Quadro 2 - Status de incubação de empresas SEBRAE (2012)

A fase de pré-incubação (hotel de projetos, pré-residência), consiste no período antes da entrada da empresa na incubadora. Assim, o empreendimento está em fase de constituição, devendo ocupar o mesmo espaço físico na incubadora, universidade ou parceiros regionais. Será assistido pela incubadora durante um prazo estipulado, visando à preparação, o desenvolvimento do projeto e a formalização do negócio. Nessa etapa, estão incluídas as empresas que pretendem iniciar os seus negócios, necessitando de um apoio em conhecimentos básicos em gestão de negócios. Um ponto importante para a préincubação de uma empresa é a apresentação de um plano de negócios estruturado, com a apresentação detalhada de todas as etapas de desenvolvimento da empresa, a partir de uma viabilidade econômicofinanceira. (TUMELERO, 2012).

O critério de seleção das empresas varia de acordo com o edital publicado pela a entidade gestora da incubadora. O edital contém informações relativas para o ingresso da empresa na incubadora de empresa, como por exemplo: modalidades de incubação, número de vagas, documentos e planos necessários, objetivo e condições do programa, taxas de inscrição, etc.

A incubação corresponde à constituição das empresas já formalizadas juridicamente e que estejam instaladas na incubadora. Atendem-se as empresas que já estejam em operação das suas atividades de negócio e que tenham o contrato de residência com a incubadora. A empresa poderá utilizar todos os benefícios que a incubadora oferece. Nesse estágio, as empresas já possuem capital, tecnologia, processo de produção e plano de negócios para a operação do empreendimento. A empresa poderá permanecer incubada até 24 (vinte e quatro) meses da data do contrato da empresa com a incubadora, sendo que o prazo poderá ser prorrogado em mais 12 (doze) meses, de acordo com a situação verificada pela incubadora. Assim, o prazo máximo de residência da empresa se constitui de 36 (trinta e seis) meses. Vale ressaltar, que os empreendimentos são avaliados no período de 6 (seis) meses, podendo o contrato ser ou não renovado, de acordo com as atividades desenvolvidas do negócio e o comprometimento do empresário. É nesse estágio que ocorre a criação e o desenvolvimento inicial do empreendimento, iniciase a comercialização de produtos, os primeiros financiamentos e rotinas organizacionais. (SEBRAE, 2012).

De acordo com o Ministério da Ciência e Tecnologia (MCT, 2001) - atualmente Ministério da Ciência, Tecnologia e Inovação (MCTI), as incubadoras oferecem uma série de facilidades e serviços, tais como:

Espaço físico: tanto individualizado, para uso particular de casa empresa, como escritórios e laboratórios de cada empresa, quanto espaço físico compartilhado, como sala de reunião, auditório, área para demonstração de produtos, processos e serviços dos empreendimentos incubados, serviços de secretariado e administrativos, laboratórios;

Recursos administrativos: serviços de recursos humanos e especializados que ajudem na gestão das empresas incubadas para a realização de suas atividades, tais como: gestão de empresas, inovação tecnológica, marketing para comercialização de produtos e orientação de mercado, contabilidade, gestão de produtos, assistência jurídica, orientação para produção, propriedade intelectual e patente, pesquisa \& desenvolvimento, contatos com financiadores.

Recursos gerenciais: apoio para capacitação, formação e treinamento, bem como de serviços de consultoria, palestras e workshops para os empresários-empreendedores, e apoio na gestão nas mais diversas áreas como comercial, recursos humanos (ou gestão de pessoas), financeiro, administrativos, projetos.

Contatos: rede de contatos com possível acesso para laboratórios e bibliotecas de universidades, bem como de outras instituições que desenvolvam atividades tecnológicas.

A pós-incubação (pós-residência) é compreendida por empresas que já passaram pelo período máximo de incubação e/ou que estão aptas para desenvolverem suas atividades no mercado. As empresas, nesse caso, estão emancipadas e não residem mais na incubadora (podem ser transferidas para um parque 
tecnológico), porém continuam vinculadas à incubadora. Assim, são empresas já constituídas que não ocupam o espaço físico da incubadora e que procuram desenvolver suas atividades de negócios no mercado.

O parque tecnológico é constituído por empresas pós-residentes ou então por empresas que não participaram do processo de incubação. São definidos como:

Um parque tecnológico é um complexo produtivo industrial e de serviços de base científicotecnológica, planejado, de caráter formal, concentrado e cooperativo, que agrega empresas cuja produção se baseia em pesquisa tecnológica desenvolvida nos centros de P\&D vinculados ao parque. Trata-se de um empreendimento promotor da cultura da inovação, da competitividade, do aumento da capacitação empresarial, fundamentado na transferência de conhecimento e tecnologia, com o objetivo de incrementar a produção de riqueza de uma região. (ANPROTEC, 2014).

Os parques tecnológicos beneficiam a região e economias onde estão instalados, pela sinergia propiciada pelas empresas inovadoras e a presença de instituições de Ciência e Tecnologia. Oferecem serviços de alto valor agregado para empresas, facilitam o fluxo de conhecimento e tecnologia, geram empregos qualificados, além do aumento da cultura e das atividades empreendedoras. Como exemplos de parques tecnológicos, de acordo com Aragão (2005), temos: Condomínio de Empresas de Alta Tecnologia de Campinas/SP; Associação de Empresas de Tecnologia, também de Campinas/SP e; Condomínio Industrial de Informática e a Associação Catarinense de Empresas de Tecnologia (ACATE) da região de Florianópolis/SC (ANPROTEC, 2014).

Aragão (2005) propõe um modelo de pós-incubação, conforme a figura 1 abaixo:

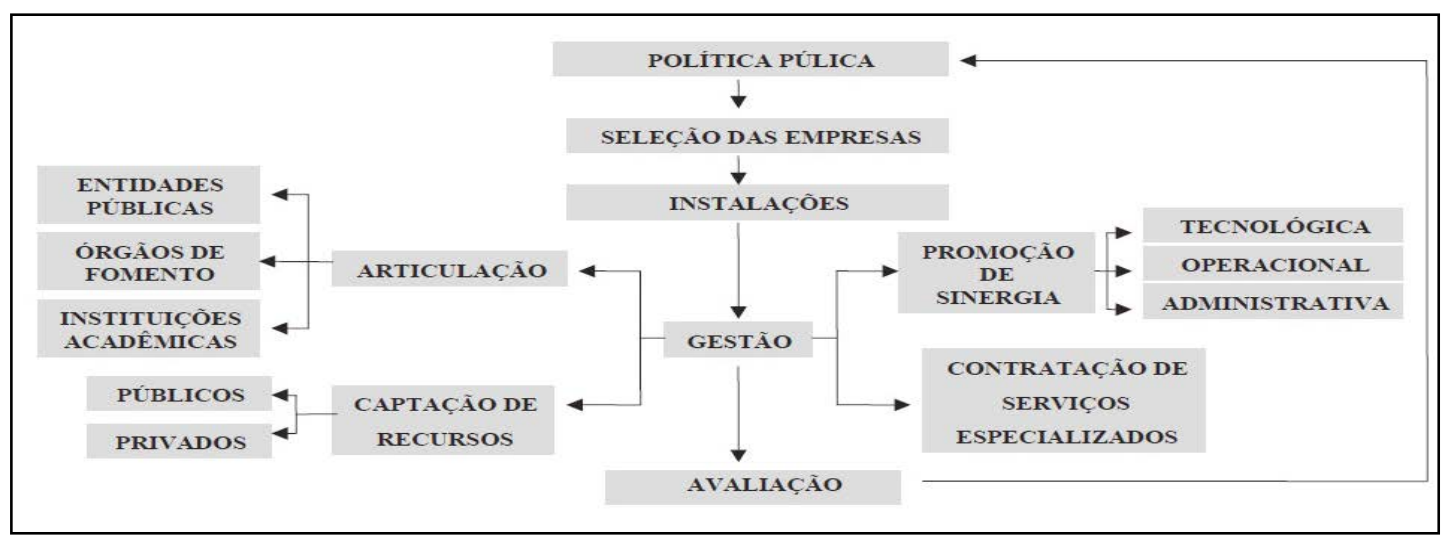

Figura 1 - Modelo de pós-incubação

Fonte: ARAGÃO, 2005, p. 84

Nesse modelo, Aragão (2005) aborda sobre temas para a constituição de condomínios empresariais (modelo de pós-incubação). A importância desses condomínios é prolongar o trabalho feito pela incubadora, porém com a empresa já instituída para realização de suas atividades no mercado. Assim, a importância é destacada:

“Estes condomínios foram instituídos com o objetivo de consolidar empresas de base tecnológica, promovendo o desenvolvimento econômico regional, com a consolidação das empresas, geração de novos produtos e serviços, renda, impostos, geração de empregos, estágios e consultorias na área tecnológica.” (ARAGÃO, 2005, p. 91)

O modelo apresenta uma série de medidas para a viabilização dos condomínios empresariais. Sobre política pública foram discutidos os seguintes pontos: revisão do diagnóstico e estudos sobre programas de desenvolvimento e crescimento local e regional; articulação entre os empresários graduados interessados, definição de um espaço físico apropriado; elaboração de um termo de compromisso; definição do órgão gestor do condomínio. O critério de seleção é definido nos programas de desenvolvimento e crescimento local e regional, levando em conta o perfil do empresário e exigindo o 
plano de negócio da empresa. Instalações, no âmbito de infraestrutura física, infraestrutura administrativa, infraestrutura de serviços especializados, que de acordo com Aragão (2005) são vendas, marketing, orientação jurídica, gestão tecnológica e de P\&D. O modelo ainda estabelece a contratação de uma entidade gestora com responsabilidades pré-definidas com um conselho que represente o empresariado. A avaliação do condomínio deve ser anual, sob responsabilidade do gestor, com objetivos e padrão de indicadores pré-definidos. A captação de recursos financeiros, no momento inicial, deverá ser feita entre entidades parceiras e os empresários, os custos posteriores, como despesas, devem ser assumidos totalmente pelos empresários. É importante a articulação com entidades parceiras como órgãos de fomento, entidades públicas, bem como a articulação com universidades e centros de pesquisa e a contratação de consultorias, assessorias, treinamento, palestras e cursos. Assim, os condomínios empresariais ou parques tecnológicos continuariam com a sinergia que existe dentro das incubadoras de empresas, pois os empresários poderiam compartilhar estrutura física, operacional e tecnológica, realizando parcerias entre as mesmas, fato que aparece como vantagem para a realização de negócios (ARAGÃO, 2005, p. 91).

Tumelero (2012) aborda a ação empreendedora sobre a mobilização e o uso de recursos. O autor na conclusão da pesquisa demonstra que há uma relação entre recursos empreendidos com a sobrevivência. Mais especificamente, utiliza quatro tipos de recursos para o estudo do sucesso de pósincubação, sendo: recursos humanos; recursos tangíveis; recursos financeiros; e recursos intangíveis. Também se concluiu que foi o conjunto de ações empreendedoras, e não ações isoladas, o ponto-chave para a sobrevivência das empresas de base tecnológica (EBT) estudadas. De acordo com o autor, as ações realizadas foram: dentro dos recursos humanos, contratação de pessoal capacitado para a área gerencial (gerentes) e para área técnica (técnicos); recursos financeiros, por obtenção de recursos por capital próprio, por capital de risco ou por meio de recursos financeiros por meio de financiamentos ou subvenções; recursos tangíveis, pela aquisição de equipamentos, softwares e demais infraestrutura física de pesquisa e; recursos intangíveis, pela realização de patenteamento e aquisição de licenças.

Ainda existem, de acordo com o SEBRAE (2012), outros tipos de status para a incubação, sendo elas: 1) graduação, empresas que já realizam plenamente suas atividades (já estão constituídas) para atuação no mercado ou que já passaram pelo período máximo de incubação, porém que não estejam mais vinculadas com a incubadora de empresa; 2) não residente/associada, que são empresas que já constituídas, porém que não participaram do processo de incubação (pré-incubação, incubação, pósincubação), estão associadas com uma incubadora para desenvolvimento gerencial, de produtos e de processos, sem ocupar um espaço físico na mesma; 3) desistente, a empresa que não encerra suas atividades, apenas perde os benefícios da fase de incubação (pré-incubação, incubação, pós-incubação), não possuem mais vínculo com a incubadora, desenvolvendo agora suas atividades por conta própria; 4) desativada, empresa que encerrou as atividades, durante o período que recebia apoio da incubadora (pode ser na fase de pré-incubação ou de incubação) e; 5) desvinculada, empresa que por algum motivo (por escolha própria ou por intermédio do conselho gestor da incubadora) rompe o vínculo existente com a mesma, nesse caso a empresa deverá ter como status anterior não residente/associada.

\section{Método de pesquisa}

Para atingir o objetivo proposto foi realizado um estudo de caso junto a quatro empresas de base tecnológica, sendo duas empresas em processo de incubação e duas empresas que se encontram em situação de pós-incubação, caracterizando o processo de pesquisa como qualitativo e exploratório. Este estudo caracteriza-se como multicasos, pois não se adotou a natureza comparativa entre as empresas investigadas.

Sobre a identificação das empresas investigadas foi inicialmente utilizada uma lista com a identificação das pequenas e médias empresas de São Carlos/SP, elaborada a partir de informações disponibilizadas pelo ParqTec e CIESP (Centro das Indústrias do Estado de São Paulo). Para a atualização desta lista referencial foram realizados alguns contatos que foram: Fundação Parque de Alta Tecnologia de São Carlos (ParqTec); Agência de Inovação USP São Carlos (Universidade de São Paulo Campus de São Carlos); Agência de Inovação UFSCAR (Universidade Federal de São Carlos), Secretaria de Desenvolvimento Sustentável, Ciência e Tecnologia da Prefeitura Municipal de São Carlos/SP; Centro 
de Desenvolvimento de Indústrias Nascentes (CEDIN), Incubadora de Empresas de Turismo e; Portal da Inovação.

Após a identificação das empresas incubadas e pós-incubadas foi realizada uma entrevista com o gestor da incubadora. Após essa etapa foram selecionadas as 02 empresas em processo de incubação e as 02 empresas que se encontram em situação de pós-incubação. A seleção de casos foi realizada a partir do levantamento das EBT, considerando os seguintes critérios: setor de atuação (empresas industriais de base tecnológica), instaladas ou com passagem em incubadoras (incubadas e pós-incubadas), pequeno porte (número de funcionários) e localização geográfica (São Carlos). Dentre as empresas identificadas, o critério adotado para seleção foi o acesso aos empresários, ou seja, por conveniência. Vale salientar que muitas empresas (tanto incubadas quanto graduadas) não responderam aos e-mails e aos telefonemas iniciais. Após a realização da entrevista com o gestor da incubadora e com a empresa incubada 01 houve uma maior facilidade para agendamento de entrevistas, pelo contato e sinergia das empresas incubadas e graduadas.

A coleta de dados foi realizada por meio de entrevistas, baseadas em um roteiro estruturado, junto aos responsáveis pela gestão das empresas e, consequentemente, pelo processo de incubação ou pósincubação das empresas. Os resultados obtidos nas entrevistas foram analisados com base na revisão da literatura realizada, relacionando conceitos de gestão de pequenas empresas e o processo de incubação e pós-incubação.

A categoria de pesquisa analisada foi sobre a incubadora (características sobre a mesma); práticas de inovação, ações voltadas a propiciar a introdução de um novo processo, produto ou serviço no mercado; especificidades de gestão: características referentes à estrutura, ao ambiente organizacional (contexto) e ao dirigente; processo de Criação de Estratégias: características deliberadas e emergentes do processo. Esperou-se responder as seguintes questões de pesquisa: a sinergia é importante para as empresas incubadas com relação às práticas de inovação e; o que se tem de diferente das empresas incubadas para as empresas graduadas?

\subsection{O processo incubação e de pós-incubação das pequenas empresas de base tecnológica}

Abaixo encontram-se as descrições das empresas incubadas (incubada 01 e incubada 02) e as empresas graduadas (graduada 03 e graduada 04).

\subsubsection{Empresa incubada 01}

A empresa incubada 01 desenvolvia soluções com automatização eletromecânica de processos e de criação de produtos integrando-as com tecnologias eletromecânicas de fabricação. Criada em 2007 e incubada em 2009, o dirigente enquadrou a área de atuação da empresa como mecânica de precisão/automação. O número total de funcionários eram 02, sendo um na administração (comercial) e um na pesquisa \& desenvolvimento (P\&D). A escolaridade e a formação dos sócios era: sócio 01 formado em engenharia mecânica e mestrado em automação e sócio 02 formado em engenharia de computação. O percentual de crescimento foi de $40 \%$ no ano de 2011, sem crescimento no ano de 2012 e de $15 \%$ no ano de 2013. A abertura da empresa se deu por uma oportunidade de negócio. A empresa funcionava como spin-off para uma outra empresa com o desenvolvimento de projeto de máquinas. Assim, nesse tipo de serviço identificaram uma oportunidade de abertura de negócio para uma empresa formal oferecer esse tipo de serviço. O objetivo e a motivação para abertura do empreendimento foram uma oportunidade de mercado. Os recursos financeiros iniciais para a abertura da empresa foram obtidos por meio de um contrato estabelecido com a empresa, pelo período de um ano, para a prestação de serviço.

Os dirigentes optaram pela incubação da empresa devido ao apoio da incubadora na área não ligada à tecnologia. Considerou-se o processo de pré-incubação como desafiador, sendo um "batismo de fogo” a entrada no mercado de negócios. Foi elaborado o plano de negócios e depois da entrada da empresa no mercado de trabalho foi realizado um estudo de mercado. O plano de negócios era considerado como ferramenta de planejamento e continua sendo utilizado depois da abertura da empresa. Os principais benefícios de ser uma empresa incubada, segundo os dirigentes, eram o apoio em áreas que não eram desenvolvidas na empresa, como no caso do marketing e do planejamento financeiro. As principais limitações por ser uma empresa incubada era a impossibilidade de espaço para crescimento 
físico. O dirigente colocava a necessidade de se avaliar o tempo de incubação de acordo com a taxa de crescimento da empresa e não por temporalidade (tempo de existência), bem como a existência de suporte de serviços técnicos e orientação para financiamentos de projetos.

O diferencial competitivo de ser incubada era o suporte, o baixo valor de aluguel cobrado pela sala, os serviços de consultoria (negócios), o apoio na questão de como agir e o que fazer (filosófica) e a sinergia entre as empresas incubadas. Os recursos utilizados pela empresa na incubadora eram: espaço físico (a instalação da empresa, laboratórios, sala de reunião); recursos gerenciais (apoio na gestão, consultorias, palestras e workshops) e; contatos (sinergia com outras empresas incubadas).

Outro serviço que o dirigente demandava e a incubadora não oferecia era a orientação para financiamento de projetos, citando que tal serviço não foi encontrado, inclusive no SEBRAE. O dirigente pontou a possibilidade encontrar investidores em venture capital (investidores anjos) e a falta de ligação entre a empresa e as instituições financiadoras. Para o proprietário a principal mudança ao se graduar seria na visão mercadológica (de encaixar a empresa no mercado - posicionamento) e maior controle geral da empresa (citou o caso das patentes).

\subsubsection{Empresa incubada 02}

A empresa incubada 02, fundada em 2011 e incubada no mesmo ano, fornecia produtos e serviços de alta qualidade e tecnologia para área animal e ambiental. Oferecia uma gama de testes de diagnósticos precisos em diferentes áreas, seguindo a necessidade do mercado consumidor. A área de atuação da empresa era a de biotecnologia. O número total de funcionários era de 05 pessoas, sendo 03 alocados na área de administração e 02 na parte de P\&D. A escolaridade e formação dos sócios era: sócio 01, mestre em biologia; sócio 02, doutora em genética; sócio 03, doutor em química analítica e; sócio 04, graduação em medicina veterinária. A empresa foi fundada com recursos obtidos a partir do projeto PIPE/FAPESP aprovado, com o objetivo de comercializar os produtos desenvolvidos pelo grupo BIOMICS do Instituto de Química de São Carlos. Decidiram empreender como oportunidade de mercado e como forma de continuar a pesquisa aplicada.

A opção dos dirigentes pelo processo de incubação foi devido ao suporte administrativo (gestão). O processo de pré-incubação se deu pelo desenvolvimento do plano de negócios para incubação e foi elaborado de forma simples para a entrada. Um outro plano de negócios foi elaborado com o auxílio de consultoria e era utilizado como ferramenta de planejamento.

Os principais benefícios de ser incubada, segundo o entrevistado, eram pelo networking (interno e externo) e pela facilidade de se conseguir financiamentos de projetos. O dirigente considerava que não havia limitação e/ou restrição por ser uma empresa incubada, bem como pontua que não existia nenhum diferencial competitivo. Os recursos utilizados durante a fase atual de incubação eram: espaço físico (instalações da empresa e sala de reunião), recursos gerenciais (consultorias, palestras e workshops) e contatos (sinergia com outras empresas incubadas). Outro tipo de serviço que a empresa necessitava e a incubadora não oferecia era o suporte gerencial, sendo exposto que existia uma parceria com o SEBRAE, mas que não acontecia constantemente.

As principais mudanças ao se graduar seria a mudança de local, a estruturação organizacional da equipe, implantação de fato do modelo CANVAS, abordagem por gestão de projetos. Já ocorreram algumas implantações de práticas organizacionais para adequação de projeto para submissão ao Ministério da Agricultura.

\subsubsection{Empresa graduada 03}

A empresa graduada 03, fundada no ano de 2010 e graduada em 2013, era especializada no desenvolvimento, fabricação e comercialização de máquinas e equipamento para ensaios científicos voltados para área de pesquisa odontológica. A área de atuação da empresa podia ser definida como médica/odontológica. O número de funcionários da empresa era de 08 incluindo um estagiário, com um na área de administração, 02 na produção e 02 no P\&D. Outros 03 funcionários estavam em outras áreas. A escolaridade e formação dos sócios era: sócio 01, mestrado em engenharia elétrica; sócio 02, doutorado em física e; sócio 03, ensino médio. Os proprietários possuíam dificuldades administrativas no gerenciamento total da empresa, ou seja, na integração de todas as áreas. O percentual de crescimento foi 
de $50 \%$ no ano de 2011, 100\% no ano de 2012, 200\% no ano de 2013. O início da empresa se deu por um projeto de mestrado e doutorado. O objetivo foi de desenvolver produtos na área odontológica. Decidiram empreender, pois viram uma oportunidade de negócio. Os recursos iniciais foram de uma parcela própria e por agências de fomento como FAPESP e CNPq.

O diferencial de ser uma empresa incubada, segundo o dirigente, era a divulgação da empresa por um custo mais baixo, por meio da participação de feiras com o recurso financeiro disponibilizado pela incubadora - a divulgação acontecia em várias feiras em que os concorrentes não participavam. Os recursos utilizados pela empresa durante a fase de incubação foram: espaço físico (laboratórios, espaço físico para a empresa, sala de reunião); recursos administrativos (recursos humanos, orientação para planejamento estratégico, contabilidade, assistência jurídica); recursos gerenciais (consultorias, palestras, workshops) e; contatos (sinergia com outras empresas incubadas). Ainda na fase de incubação a empresa necessitava de outros serviços que a incubadora não oferecia como a regulamentação jurídica para produtos odontológicos, ANVISA e Vigilância Sanitária.

As principais mudanças ao se graduar foram a melhoria do espaço físico, para se ficar com uma “cara a mais de empresa”, passando uma maior confiança para os clientes. O processo de graduação partiu do empresário e foram destacadas diferenças para uma "empresa normal” e melhorias por sair da incubação, tais como maior espaço físico e maior credibilidade com clientes.

Os tipos de serviço que poderiam ser oferecidos a uma empresa pós-incubada, identificados pelo dirigente entrevistado, foram a extensão dos contatos e parceria, os mesmos benefícios como o SEBRAE, sendo que alguns cursos só são oferecidos para empresas incubadas. A empresa mantinha contato com a incubadora - participando de cursos indicados e/ou oferecidos pela incubadora.

Foi destacado como diferencial de ser uma empresa incubada o fato de "aprender com outras empresas durante o período de incubação, com uma perspectiva de micromercado e, aprender a resolver problemas com mais rapidez”, como as questões relacionadas a recursos humanos, por exemplo. O início do planejamento da empresa ocorreu no processo de planejamento para projetos, no qual não se utilizava modelos e acontecia com a periodicidade mensal. Acontecia no período de um mês pelas mudanças de mercado e assim, como forma de adaptação. Cita a dificuldade da implementação de alguns planejamentos, por não condizerem com a realidade da empresa e a dificuldade de alcançar metas, pelo fato de elas serem criadas apenas como requisito do planejamento. Por fim, cita que manteve o planejamento inicial.

Quanto às mudanças nas práticas de inovação do período de incubação para o de graduação, o dirigente coloca que inicialmente as práticas de inovação eram desenvolvidas a partir das escolhas da empresa e que atualmente a inovação está no que o cliente precisa (demanda do mercado).

\subsubsection{Empresa graduada 04}

A empresa graduada 04, fundada em 2003 e graduada em 2009, era uma empresa de desenvolvimento de tecnologia e integração de sistemas que vinha atuando com estado da arte das ferramentas computacionais para automação e controle industriais, monitoramento de processos e máquinas, gerenciamento e controle da produção e tecnologia da informação. A área de atuação da empresa graduada 04 era mecânica de precisão/automação. O número total de funcionários da empresa eram 04, sendo 01 na administração e 03 na produção. A área de P\&D foi transferida para outra empresa do grupo empresarial. A escolaridade e a formação dos sócios eram: sócio 01, doutorado em engenharia mecânica e sócio 02, doutorado em engenharia mecânica. O percentual de crescimento foi de $20 \%$ no ano de 2011, um pequeno crescimento no de 2012 e de estagnação no ano de 2013. O início da empresa se deu com um projeto de doutorado desenvolvido na Universidade de São Paulo (USP) e contou com o conhecimento e de parceiras como o FIPAI e desenvolvimento de alguns projetos. O objetivo foi de atender a algumas empresas. Decidiram empreender como oportunidade de mercado. Os recursos financeiros iniciais para a abertura da empresa foram próprios (iniciaram as atividades na casa de um dos proprietários).

A decisão de incubar a empresa foi para o desenvolvimento da área de $P \& D$ e pela estrutura da incubadora, com auxílio na gestão e com inúmeros benefícios. O processo de pré-incubação se deu por meio de serviços prestados como pelo dirigente, como doutorando na época. A empresa não tinha uma 
sede no início. Passou a contar com uma sede com a entrada no ParqTec, com a elaboração do plano de negócios e formalização dos projetos desenvolvidos. O plano de negócios era utilizado como ferramenta de planejamento. E, inclusive passou por 03 revisões desde que a primeira versão foi elaborada há 07 anos. A última mudança se deu com a entrada de um sócio investidor e com as mudanças na área regulatória, com o intuito de estruturar e valorizar o negócio.

Os principais benefícios de ser uma empresa incubada concentravam-se na estrutura (sala de reuniões), suporte área de gestão, suporte financeiro para participação de feiras e congressos e apoio para financiamentos (FAPESP). A principal limitação e/ou restrição de ser uma empresa incubada era o espaço físico limitado, considerado pequeno pelo dirigente. O diferencial competitivo de ser uma empresa incubada era o desenvolvimento da área técnica, fato que é reconhecido pelo mercado e clientes.

Os recursos utilizados pela empresa durante a fase de incubação foram: espaço físico (laboratórios, espaço físico para a empresa, sala de reunião, serviço de secretariado); recursos administrativos (recursos humanos, orientação para inovação tecnológica, orientação para o planejamento estratégico a partir da cobrança da incubadora, apoio indireto para pesquisa \& desenvolvimento a partir da sinergia ali estabelecida); recursos gerenciais (apoio na gestão, consultorias, palestras e workshops) e contatos (sinergia com outras empresas incubadas). Ainda no período de incubação, a empresa necessitava de um serviço não ofertado pela incubadora, que era a assessoria ou auxílio contábil e jurídico.

A graduação não trouxe mudanças relevantes, pois o processo foi paulatino, sem impactos e contou com a devida preparação. O processo de graduação aconteceu de forma madura, em que deixou uma parte na incubadora e outra parte saiu, acontecendo sem maiores dificuldades. Os tipos de serviços que poderiam ser oferecidos a uma empresa pós-incubada, de acordo com necessidade identificada pelo dirigente, eram os relacionados à assistência jurídica, principalmente na parte de contratos. A empresa mantém contato e vínculo com a incubadora.

O diferencial por ter sido incubada foi o de iniciar um negócio de forma estruturada, “de traçar um caminho para a empresa a partir do plano de negócios, com uma estruturação da gestão da empresa”. O processo de planejamento da empresa era informal no início, tornando-se mais formal com a obrigação de elaboração de um plano de negócios, exigido como requisito na incubação, pela incubadora e pela FAPESP - enviado para obtenção de recursos para projetos. As mudanças com relação às práticas de inovação do período de incubação para a graduação foram o aumento de recursos e o volume/dimensão dos projetos, sendo que a empresa ainda busca continuamente novas práticas de inovação.

\section{Discussão dos dados}

A incubadora denominada Centro Incubador de Empresas Tecnológicas (CINET) está vinculada ao Parque Tecnológico (ParqTec). Segundo o gestor da incubadora o ano de fundação é 1984 (a literatura apresenta como 1985) e atualmente conta com 18 empresas incubadas e gera aproximadamente 70 empregos diretos. Não há registros sobre o faturamento anual das empresas incubadas.

O processo de pré-incubação se dá por meio da elaboração de um plano de negócios e de um plano de viabilidade econômico orientando, quando há necessidade, para que os proponentes atendam aos requisitos necessários de produto/serviço tecnológico com certo grau de inovação. Considera-se que a importância da incubadora para a inovação das empresas se dá pelo processo de incubação, que é fundamental para que a empresa inicie seu processo de maneira correta contando com o apoio de profissionais que auxiliam na aplicação de métodos e ferramentas de gestão e consultorias nas mais diversas áreas, principalmente naquelas em que o empresário apresenta maiores dificuldades. Ao apoiar a elaboração de um plano de negócios a incubadora já oferece apoio sobre o planejamento estratégico.

A definição de o que é incubadora, tanto pela ANPROTEC (2012) quanto pelo SEBRAE (2012), vai ao encontro com o que foi observado na pesquisa com a incubadora e as empresas. A incubadora é importante para o desenvolvimento empresarial e criação da cultura empreendedora, oferecendo suporte dos mais variados tipos para que a empresa cresça e, posteriormente possa estar no mercado de negócios. Esse apoio foi importante para o tipo de empresa em questão, que pelo fato de serem altamente técnicas, não possuía conhecimento gerencial. 
O principal benefício de ser uma empresa incubada é o apoio em áreas não desenvolvidas nas empresas, como marketing e planejamento financeiro, rede de relacionamentos (interno e externo) e sinergia com outras empresas incubadas, infraestrutura da incubadora, facilidade para financiamentos etc. A principal limitação e restrição de ser uma empresa incubada é a questão do pequeno espaço físico oferecido, que após um tempo, se torna inviável para o crescimento da empresa. Outras limitações apontadas são a falta de apoio e serviços técnicos e a falta de orientação para financiamentos de projetos (empresa incubada 01).

Como diferencial competitivo de ser uma empresa incubada estão: suporte gerencial e administrativo, baixo valor do aluguel, sinergia com outras empresas, divulgação da empresa com custos mais baixos (feiras) e valorização do mercado pela relação com a tecnologia e área acadêmica. Apenas a empresa incubada 02 não apontou nenhuma limitação de ser uma empresa incubada, tão pouco um diferencial competitivo de ser uma empresa incubada. Sintetiza-se algumas dessas informações sobre os benefícios, limitações e diferencias das empresas incubadas no quadro 3.

\begin{tabular}{|c|c|c|}
\hline \multicolumn{3}{|c|}{ Benefícios, dificuldades e diferencias sobre as empresas incubadas a partir das } \\
entrevistas realizadas
\end{tabular}

Quadro 3 - Benefícios, dificuldades e diferencias sobre as empresas incubadas a partir das entrevistas realizadas

A forma de captação de recursos se deu principalmente com subvenções de órgãos de fomento. A utilização de capital próprio também foi identificada. A doação ou investimentos privados ainda eram pouco utilizados no contexto brasileiro. As consultorias às empresas incubadas eram oferecidas pelo SEBRAE, o espaço físico era cedido pela prefeitura municipal, ou então, como no caso da incubadora das empresas deste estudo, o espaço físico era próprio.

O prazo da graduação era também definido pelo regimento da incubadora. Na maioria dos casos o prazo máximo é de 24 meses, podendo ser prorrogado por mais 12 meses. Assim, percebem-se diferenças, conforme apontado por Aragão (2005) sobre programas internacionais de incubação (Estados Unidos, Canadá, China e Rússia) e o programa brasileiro de incubação.

A incubadora em questão (Centro Incubador de Empresas Tecnológicas - CINET), do Parque Tecnológico de São Carlos (ParqTec), incuba empresas do setor de tecnologia que veem na inovação tecnológica um diferencial no negócio, produtos com alto valor agregado com utilização de tecnologia ou de pesquisas científicas e impacto estadual ou nacional. Percebeu-se que não estão claros os serviços oferecidos pela incubadora para as empresas entrevistas. $\mathrm{O}$ gestor da incubadora afirmou o oferecimento dos seguintes benefícios: espaço físico (laboratórios, espaço físico para a empresa, sala de reunião e serviço de secretariado); recursos administrativos (orientação para inovação tecnológica, orientação para 
planejamento estratégico, assistência jurídica, apoio para pesquisa \& desenvolvimento) não sendo ofertados serviços de recursos humanos e de contabilidade; recursos gerenciais (apoio na gestão, consultorias, palestras e workshops) e; contatos (universidades, outras instituições tecnológicas e sinergias com outras empresas incubadas). Com relação a outros tipos de serviços relevantes que poderiam ser oferecidos pela incubadora estão a orientação para financiamentos, o suporte gerencial constante próprio da incubadora, o apoio para regulamentação específica para a área da empresa e o auxílio contábil e jurídico. O quadro 4 sintetiza algumas dessas informações logo a baixo.

\begin{tabular}{|c|c|}
\hline \multicolumn{2}{|c|}{$\begin{array}{c}\text { Serviços oferecidos ou que poderiam ser oferecidos } \\
\text { pela incubadora entrevistada }\end{array}$} \\
\hline Oferecidos & $\begin{array}{c}\text { Que poderiam ser } \\
\text { oferecidos }\end{array}$ \\
\hline $\begin{array}{c}\text { Espaço físico (laboratórios, } \\
\text { espaço físico para a } \\
\text { empresa, sala de reunião e } \\
\text { serviço de secretariado) }\end{array}$ & $\begin{array}{c}\text { Serviços de recursos } \\
\text { humanos e de contabilidade }\end{array}$ \\
\hline $\begin{array}{c}\text { Recursos administrativos } \\
\text { (orientação para inovação } \\
\text { tecnológica, orientação } \\
\text { para planejamento } \\
\text { estratégico, assistência } \\
\text { jurídica, apoio para } \\
\text { pesquisa \& } \\
\text { desenvolvimento) }\end{array}$ & $\begin{array}{c}\text { Orientação para } \\
\text { financiamentos }\end{array}$ \\
\hline $\begin{array}{c}\text { Recursos gerenciais (apoio } \\
\text { na gestão, consultorias, } \\
\text { palestras e workshops) }\end{array}$ & $\begin{array}{c}\text { Suporte gerencial constante } \\
\text { próprio da incubadora }\end{array}$ \\
\hline $\begin{array}{c}\text { Contatos (universidades, } \\
\text { outras instituições } \\
\text { tecnológicas e sinergias } \\
\text { com outras empresas } \\
\text { incubadas) }\end{array}$ & $\begin{array}{c}\text { Apoio para regulamentação } \\
\text { específica para a área da } \\
\text { empresa e o auxílio contábil } \\
\text { e jurídico. }\end{array}$ \\
\hline
\end{tabular}

Quadro 4 - Serviços oferecidos ou que poderiam ser oferecidos pela incubadora entrevistada

Com relação à fase de pré-incubação (do período antes da entrada na incubadora) percebe-se realmente a importância do plano de negócios e do plano de viabilidade econômica para as primeiras orientações e para o estabelecimento do negócio. Os empresários decidiram incubar as empresas principalmente pelo apoio gerencial e administrativo, pelo fato do aluguel ser barato (melhor custo benefício), pela sinergia com as outras empresas incubadas e pelo desenvolvimento do P\&D da empresa, como citado acima. O processo de pré-incubação é considerado um período desafiador, mesmo para algumas das empresas que já existiam antes da entrada na incubadora - foram oriundas de projetos de pesquisas desenvolvidos nas universidades. O plano de negócios é utilizado como ferramenta de planejamento e guia para todas as empresas, mesmo após a abertura e início das atividades.

As empresas incubadas esperam que as principais mudanças ao se graduar sejam uma melhor visão de mercado e melhor estruturação da empresa (empresa incubada 01) e mudança de local e melhor estruturação organizacional (empresa incubada 02). Já as empresas graduadas apontaram como principais mudanças ao se graduar, a ida para um local maior (empresa graduada 03).

A pós-incubação é o período que a empresa sai da incubadora (espaço físico), porém continua vinculada a mesma. No processo de graduação, que parte do empresário, há um amadurecimento da empresa. No caso da empresa graduada 04 foi um processo mais longo e ainda há uma parte da empresa incubada. Os tipos de serviços identificados que poderiam ser oferecidos a uma empresa pós-incubada 
são: capacitação por meio de cursos e palestras oferecidos para as empresas incubadas e assistência jurídica na área de contratos. O diferencial por ter sido uma empresa incubada é o de traçar de forma intencional um caminho, além da capacitação em questões gerenciais.

\section{Conclusão}

O estudo em questão visou abordar o período de incubação e pós-incubação das pequenas empresas de base tecnológica. As pequenas empresas de base tecnológica apresentam centralização administrativa, estratégia informal ou intuitiva, sistema de informações informal, estrutura simples com poucas linhas hierárquicas, alto teor de inovação e dificuldade gerenciais e administrativas. A incubação é outro aspecto relevante no contexto de desenvolvimento dessas empresas. Por serem criadas por pessoal altamente qualificado e de formação técnica, as empresas passam por dificuldades e crises, advindas de problemas administrativos e gerenciais. Com os benefícios oferecidos pela incubadora de empresas conseguem sanar tais dificuldades e obter uma orientação específica de mercado. A sinergia encontrada na incubadora também é motivo de destaque. O ambiente em que encontram é favorável para o desenvolvimento de novas práticas. Nas empresas graduadas, percebe-se uma maior maturidade administrativa, afetando o processo de criação de estratégias e as práticas de inovação que tendem a ficar mais formais.

Quanto às questões de pesquisa tem-se que a sinergia do processo de incubação influencia as práticas de inovação. Todas as empresas responderam que um diferencial de ser incubada é justamente a de estar em um ambiente com outras empresas, servindo como parâmetro de desenvolvimento, troca de informações e contatos, que sem dúvida propiciam para o desenvolvimento de práticas de inovação. As variáveis preponderantes nas práticas de inovação das empresas graduadas são a mudança de foco no desenvolvimento de novos produtos e serviços, que antes eram propostos pelos dirigentes das empresas, passando a se desenvolver a partir da demanda de mercado e solicitação de clientes específicos; a estruturação da empresa, sobretudo a área de Pesquisa \& Desenvolvimento (P\&D); contratação de funcionários qualificados e de caráter técnico; aumento do espaço físico da empresa e aumento de recursos disponíveis, em especial as subvenções de agências de fomento. A incubação e a graduação também são consideradas eventos marcantes no ciclo de vida de tais empresas. Com relação as diferenças entre as empresas incubadas e pós-incubadas temos uma maior formalidade e deliberação para as práticas de inovação e para o processo de criação de estratégias. Além disso, notou-se que as empresas graduadas contam com mais recursos, funcionários, estruturação organizacional devido ao fato de já terem completado todo o ciclo de incubação e por estarem mais avançadas no ciclo de desenvolvimento.

Alguns apontamentos são realizados visando a melhoria de gestão de tais empresas, como: com relação às empresas incubadas: 1) faz-se necessária a busca de uma melhor estruturação da empresa para que usufruam dos benefícios proporcionados pelo período de incubação e possam se desenvolver ao máximo administrativamente e gerencialmente, minimizando dificuldades futuras; 2) a especificação clara da estratégia mercadológica em seu plano de negócios. Identifica-se como uma primeira dificuldade o relacionamento com o mercado, especificamente clientes e fornecedores; com relação às empresas graduadas, nota-se: 1) a necessidade de apoio de gestão ou a contratação de funcionários com conhecimento gerencial, que utilizem ferramentas ou modelos para a elaboração de suas estratégias e; 2) busquem a união das empresas graduadas, em um parque tecnológico ou condomínio empresarial, para que possam usufruir da sinergia que seria propiciada com essa possibilidade.

Como sugestão de novos estudos, coloca-se a possibilidade de análise do papel do administrador, que é elemento principal dentro da pequena empresa de base tecnológica e também para as práticas de inovação. A pesquisa atingiu o objetivo proposto de analisar o período de incubação e pós-incubação das pequenas empresas de base tecnológica. Portanto, com a realização da pesquisa espera-se ter contribuído com o avanço do conhecimento dessa área e que possibilite o desenvolvimento de novas pesquisas relacionadas ao processo de incubação.

\section{Referências}

ALMEIDA, M. The evolution of the incubator movement in Brazil. International Journal of Technology and Globalisation, v. 1, n. 2, p. 258-277, 2005. 
ANPROTEC. ASSOCIAÇÃO NACIONAL DE ENTIDADES PROMOTORAS DE EMPREENDIMENTOS INOVADORES. ANPROTEC, 2013. Incubadoras e parques. Disponível em <http://anprotec.org.br/site/incubadoras-e-parques> Acesso em 30/04/2014.

ANPROTEC. ASSOCIAÇÃO NACIONAL DE ENTIDADES PROMOTORAS DE EMPREENDIMENTOS INOVADORES. ANPROTEC. Relatório Técnico de Estudo, Análise e Proposições sobre as Incubadoras de Empresas no Brasil. Brasília, 2012.

ARAGÃO, I. Pós-incubação de empresas de base tecnológica. Tese (Doutorado) - Faculdade de Economia e Administração e Contabilidade, FEA/USP, 2005

AUDRETSCH, D. B. Innovation, growth and survival. International Journal of Industrial Organization, n.13, p. 441-457, 1995.

CARVALHO, L. M. C.; GALINA, S. V. The role of business incubators for start-ups development in Brazil and Portugal. World Journal of Entrepreneurship, Management and Sustainable Development, v. 11, n. 4, p. 256-267, 2015.

D’AMBOISE, G.; MULDOWNEY, M. Management theory for small business: attempts and requirements. Academy of Management Review, v. 13, n. 2, p. 236-240, 1988.

DAMANPOUR, F. Organizational complexity and innovation: developing and testing multiple contingency models. Management Science, v 42, n. 5, 693-716, 1996.

DANDRIGE, T. C. Children are not "little grown-ups": small business needs its own organizational theory. Journal of small business management. v.17, n.2, p. 53-53, 1979.

DAY, J. The value and importance of the small firm to the world economy. European Journal of Marketing, Bradford, v. 34, n.9/10, p. 1033, 2000.

EKZTOWITZ, H.; MELLO, J. M. C.; ALMEIDA, M. Towards “meta-innovation” in Brazil: the evolution of the incubator and the emergence of a triple helix. Research Policy, v. 34, n. 4, p. 411-424, 2005.

FERNANDES, A. C.; CÔRTES, M. R.; OISHI, J. Innovation characteristics of small and médium sized technology-based firms in São Paulo, Brazil. INTERNATIONAL CONFERENCE ON TECHNOLOGY POLICY AND INNOVATION, 4, Curitiba, Anais..., Curitiba, PR, 2000.

FONSECA. S. A.; KRUGLIANKSAS, I. Inovação em microempresas de setores tradicionais: Estudo de caso em incubadoras brasileiras. In: SBRAGIA, R.; STAL, E. Tecnologia e Inovação: Experiências de gestão na micro e pequena empresa. São Paulo: PGT/USP, p. 89-119, 2002.

MINISTÉRIO DA CIÊNCIA E TECNOLOGIA (MCT). Manual para a implantação de incubadoras de empresas. Programa Nacional de Apoio as Incubadoras de Empresas - PNI, 41 p. Relatório técnico, 2001.

PORTAL BRASIL. Mapa das Micro e Pequenas Empresas, $2013 . \quad$ Disponível em $<$ http://www.brasil.gov.br/empeendedor/empreendedorismo-hoje/o-mapa-das-micro-e-pequenas-empresas> Acesso em 20/04/14.

SEBRAE. Critérios e conceitos para classificações de empresas, 2012. Disponível em <http://arquivopdf.sebrae.com.br/uf/goias/indicadores-das-mpe/classificacao-empresarial> Acesso em 21/05/2014.

SEBRAE. MPEs de base tecnológica: conceituação, formas de financiamento e análise de casos brasileiros, 2001.

SERVIÇO BRASILEIRO DE APOIO ÀS MICRO E PEQUENAS EMPRESAS. Programa SEBRAE SP de Incubadoras de Empresas: Manual de Procedimentos. Disponível em < http://www.sebraesp.com.br/arquivos_site/parcerias/>. 2012. Acesso em: 30/04/2014.

TERENCE, A. C. F. Processo de criação de estratégias em pequenas empresas. Tese (Doutorado) - Escola de Engenharia de São Carlos, USP, 2008.

TOKORMIAN, A. L. V.; MEDEIROS, J. S. Avaliação do polo tecnológico de São Carlos: papel dos parceiros e formas de articulação. Revista de Administração, v. 29, n.2, p. 49-62, 1994. 
TUMELERO, C. Sobrevivência de empresas de base tecnológica pós-incubadas. Dissertação (Mestrado) - Faculdade de Economia e Administração e Contabilidade, FEA/USP, 2012. 